\title{
Risk Factors and Nursing Countermeasures of Ventilator-Associated Pneumonia in Children in the Intensive Care Unit
}

\author{
Rong Chen, Yu Liu, Xiaohong Zhang, Qin Yang $\mathbb{D}$, and Xiao Wang (iD \\ Department of ICU, Xiangyang Central Hospital, Affiliated Hospital of Hubei University of Arts and Science, Xiangyang,
} Hubei 441021, China

Correspondence should be addressed to Qin Yang; yangqin6177@163.com and Xiao Wang; 1213081682@qq.com

Received 28 December 2021; Revised 12 January 2022; Accepted 17 January 2022; Published 17 February 2022

Academic Editor: Enas Abdulhay

Copyright (c) 2022 Rong Chen et al. This is an open access article distributed under the Creative Commons Attribution License, which permits unrestricted use, distribution, and reproduction in any medium, provided the original work is properly cited.

Objective. This study discussed and analyzed the risk factors and nursing countermeasures of ventilator-associated pneumonia (VAP) in the children intensive care unit (ICU). Methods. In this study, 155 children with mechanical ventilation in the pediatric intensive care unit from Oct. 2018 to Oct. 2020 were chosen as research objects. We retrospectively analyzed the clinical data of children and divided them into VAP groups and non-VAP groups according to the occurrence of VAP. Subsequently, we adopted a univariate and multivariate logistic regression model to analyze and clarify the risk factors of VAP and formulated the corresponding nursing countermeasures. Results. 49 cases of total research objects had occurred VAP, with an infection rate of $31.62 \%$. The primary pathogenic bacteria were Gram-negative bacteria (43/70, 61.43\%). According to multivariate logistic regression analysis, the duration of mechanical ventilation, invasive procedures, and application of hormones and antacids are all independent risk factors for VAP in pediatric ICU. The VPA group had longer hospital stay than the non-VAP group, and the difference was statistically significant $((20.92 \pm 4.16) \mathrm{d},(15.24 \pm 3.77) \mathrm{d}, t=8.4383, P \leq 0.001)$. The hospitalization cost of the VPA group was substantially higher than that of the non-VAP Group ((45.8 \pm 10.4$)$ thousand Yuan, $(33.2 \pm 4.3)$ thousand Yuan, $t=10.6822, P \leq 0.001)$. Conclusion. Children admitted to the pediatric ICU have a high VAP incidence. The primary pathogenic bacteria are Gram-negative bacteria. As the occurrence of VAP is closely related to a variety of factors, we should take targeted nursing countermeasures to reduce the duration of mechanical ventilation and the frequency of invasive operations and use the hormone and antacids rationally to reduce the risk of VAP and improve the prognosis.

\section{Introduction}

Most children admitted to the pediatric intensive care unit (ICU) have severe pneumonia, myocarditis, encephalitis, hand-foot-and-mouth disease, etc. Children often need to use respiratory support to get through the dangerous period due to respiratory disorders or respiratory failure, but the application of ventilator is easy to cause complications such as pulmonary injury, displacement of tracheal intubation, septic shock, and respiratory-associated pneumonia (VAP) $[1,2]$. VAP refers to pulmonary infection that occurs $48 \mathrm{~h}$ after endotracheal intubation or tracheostomy with mechanical ventilation or $48 \mathrm{~h}$ after removal of a mechanical ventilation tube, which has high morbidity and fatality rate
$[3,4]$. VAP prolongs the length of hospital stay and surcharges medical costs and increases the clinical mortality rate and affects the prognosis of children [5]. In recent years, the risk factors of VAP have been the hot spot in the analysis and research of the intensive care field. According to the work in [6-8], the occurrence of VAP is closely related to clinical nursing operations. Therefore, it is of great significance to take effective preventive and nursing measures to reduce VAP risks in the pediatric ICU. This study retrospectively analyzed the clinical data of the 155 mechanically ventilated children in the pediatric ICU of our hospital from Oct. 2018 to Oct. 2020, aiming to clarify the risk factors, pathogen distribution characteristics, and prognosis of children admitted in our pediatric ICU with VAP, 
meanwhile, to find targeted nursing countermeasures for the pediatric ICU of our hospital, and to provide a theoretical basis for clinical prevention of VAP.

\section{Cases and Methods}

2.1. General Data. 155 children with mechanical ventilation in the pediatric ICU from Oct. 2018 to Oct. 2020 were chosen as research objects. The objects included 81 males and 74 females, with an average age of $(7.83 \pm 2.46)$ years; the average duration of mechanical ventilation was $(7.35 \pm 3.12)$ $\mathrm{d}$, and the average length of hospital stay was $(18.52 \pm 3.05) \mathrm{d}$. This study was carried out after acquiring approval from the ethics committee of our hospital.

2.2. Inclusion and Exclusion Criteria. Inclusion criteria: (1) the age of the patients ranged from 3 to 12 years; (2) all children were treated with invasive ventilation, and the duration of mechanical ventilation was $\geq 48 \mathrm{~d}$; (3) children tended to be in stable conditions, or without progressive aggravation; and (4) the clinical data of children were complete.

Exclusion criteria: (1) children that were diagnosed with severe pneumonia before mechanical ventilation; (2) children with other serious diseases; (3) children with conscious or cognitive disorders, or with mental disorders; or (4) those discharged or died during treatment.

2.3. Diagnostic Criteria of VAP. We performed chest X-ray examination on children who have received mechanical ventilation for $48 \mathrm{~h}$ or within $48 \mathrm{~h}$ of withdrawing the ventilator and intubation. X-ray shows infiltrative shadows or new inflammatory lesions in the lungs, and moist rales could be heard during auscultation. According to the diagnostic criteria of VAP in Guidelines for the Diagnosis and Treatment of Hospital-Acquired Pneumonia of the Chinese Society of Respiratory Medicine [9], the child met any of the following two conditions simultaneously: (1) body temperature $>38.5^{\circ} \mathrm{C}$ or $<36.5^{\circ} \mathrm{C}$, and there were no other obvious external causes; (2) the white blood cell (WBC) $>10 \times 10^{9} / \mathrm{L}$ or $<4.0 \times 10^{9} / \mathrm{L}$; (3) increased or purulent respiratory secretions; and (4) new pathogenic bacteria were cultured in secretions.

2.4. Methods. We took 155 children with mechanical ventilation in the pediatric intensive care unit from Oct. 2018 to Oct. 2020 as research objects, retrospectively analyzed their clinical data, and divided them into VAP groups and nonVAP groups according to VAP occurrence. The children's general clinical data include gender, age, underlying diseases, blood transfusion experience, nutritional status, diagnosis, and treatment conditions such as nutritional support methods, intubation methods, application of antibiotics and hormones, and duration of mechanical ventilation retrospectively analyzed. We performed a singlefactor analysis on the respective risk factors of the two groups and subsequently incorporated the obtained highrisk factors into the logistic regression model for analysis.

2.5. Statistical Analysis. We adopted the statistical software SPSS19.0 to analyze and process the data included. The measurement data were expressed as $(\bar{x} \pm s)$, and comparison between groups was by the $t$-test of independent samples; the enumeration data were described by percentage, and the results were taken by $\chi^{2} . P<0.05$ refers to the statistically significant difference. The multivariate logistic regression analysis included the selected statistically significant variables to determine independent risk factors by steps, and the significance level $\alpha=0.05$.

\section{Results}

3.1. General Clinical Data in the Pediatric ICU. 49 cases of real research objects had occurred VAP, the infection rate was $31.62 \%$, and a total of 70 pathogens were detected (Table 1). According to univariate analysis, the general clinical data of patients, including age, underlying diseases, experience of blood transfusion, and malnutrition, were all connected with the occurrence of VAP (Table 2).

3.2. Univariate Analysis of Medication and Diagnosis. Univariate analysis results indicated that the diagnosis and treatment, such as duration of mechanical ventilation, length of ICU stay, and application of invasive operations and hormones and antibiotics, were all concerned with the occurrence of VAP, as shown in Table 3. Variable assignment of VAP in the pediatric ICU: the variable assignment of VAP in the child intensive care unit is shown in Table 4. According to multivariate logistic regression analysis, the duration of mechanical ventilation, invasive procedures, and application of hormones and antacids are all independent risk factors for VAP in the pediatric ICU (Table 5).

3.3. Comparison of Treatment between the Two Groups of Children in the ICU. The VPA group had longer hospital stay than the non-VAP group, and the difference was statistically significant $\quad((20.92 \pm 4.16) \mathrm{d}, \quad(15.24 \pm 3.77) \mathrm{d}, \quad t=8.4383$, $P \leq 0.001)$; the hospitalization cost of the VPA group was substantially higher than that of the non-VAP group $[(44.58 \pm 1.04)$ ten thousand Yuan, $(3.32 \pm 0.43)$ ten thousand Yuan, $t=10.6822, P \leq 0.001$ ) (Table 6 and Figure 1 ).

\section{Discussion}

Mechanical ventilation is a treatment that applies a ventilator to alter or replace patient's active breathing. It relies on auxiliary equipment to establish the pressure difference between the airway orifice and the alveoli of patient, thus alleviating the respiratory failure or dyspnea of the patient $[10,11]$. According to the literature, over $20 \%$ children in the pediatric ICU will be treated with mechanical ventilation during treatment [12]. The complication of VAP in children often occurs with the widespread application of mechanical ventilation in the pediatric ICU. For every $24 \mathrm{~h}$ increase in 
TABLE 1: Distribution of pathogenic bacteria of VAP in the pediatric ICU.

\begin{tabular}{lcc}
\hline Species of pathogenic bacteria & Quantity & Composition ratio (\%) \\
\hline Gram-negative bacteria & 43 & 61.43 \\
Acinetobacter baumannii & 19 & 27.14 \\
Klebsiella pneumoniae & 8 & 11.43 \\
Pseudomonas aeruginosa & 8 & 11.43 \\
Stenotrophomonas maltophilia & 4 & 5.71 \\
Escherichia coli & 3 & 4.29 \\
Enterobacter cloacae & 1 & 1.43 \\
Gram-positive bacteria & 23 & 32.86 \\
Staphylococcus aureus & 15 & 21.43 \\
Staphylococcus epidermidis & 5 & 7.14 \\
Enterococcus & 3 & 4.29 \\
Fungi & 4 & 5.71 \\
Candida albicans & 4 & 5.71 \\
Total & 70 & 100
\end{tabular}

TABLE 2: Univariate analysis of general clinical data on VAP in the pediatric ICU.

\begin{tabular}{|c|c|c|c|c|}
\hline General clinical data & VAP group $(n=49)$ & Non-VAP group $(n=106)$ & $X^{2}$ & $P$ \\
\hline Gender (cases) & & & 0.0185 & 0.8918 \\
\hline Male & 26 & 55 & & \\
\hline Female & 23 & 51 & & \\
\hline Age (yd) & & & 11.9029 & 0.0006 \\
\hline$<7$ & 28 & 30 & & \\
\hline$\geq 7$ & 21 & 76 & & \\
\hline Underlying disease (cases) & & & 12.2373 & 0.0005 \\
\hline Yes & 26 & 26 & & \\
\hline No & 23 & 80 & & \\
\hline Experience of blood transfusion (case) & & & 12.4831 & 0.0004 \\
\hline Yes & 25 & 24 & & \\
\hline No & 24 & 82 & & \\
\hline Malnutrition (cases) & & & 5.7306 & 0.0167 \\
\hline Yes & 13 & 12 & & \\
\hline No & 36 & 94 & & \\
\hline
\end{tabular}

time of mechanical ventilation, the probability of VAP will increase by $1 \%$ to $3 \%$. According to related data [13], the incidence rate of VAP in children with mechanical ventilation was $9 \%-68 \%$, the mortality was $24 \%-76 \%$, and the incidence tends to increase year by year. Through the investigation of pathogenic bacteria changes in VAP children, it has been found in related studies that the primary pathogenic bacteria of VAP are Gram-negative bacteria, which have multiple drug resistance [14]. The primary pathogens of VAP in the pediatric ICU, of our hospital during the past 2 years, are Acinetobacter baumannii, Staphylococcus aureus, Klebsiella pneumoniae, and Pseudomonas aeruginosa. These results are consistent with those of most research [15-17].

The results of this study's univariate analysis and multivariate logistic regression analysis showed that the duration of mechanical ventilation, invasive operations, and the application of hormones and antacids are all independent risk factors for VAP in the pediatric ICU. The duration of mechanical ventilation is positively correlated with VAP incidence, and the incidence of VAP increases with the extension of mechanical ventilation. This is because the immunity of children under the growing and developing stage is weak due to incomplete body development. During mechanical ventilation, the normal physiological barriers of the nose, throat, and tracheal mucosa of the child are vulnerable to being damaged, which reduces the movement capacity of cilia and increases the viscosity of sputum, as well as chances pathogen invasion and reproduction, thus leading to the occurrence of nosocomial infection [18, 19]. The long-term mechanical ventilation also aggravates lung injury. The long-term upper respiratory tract stimulation of patients increases the accumulation of sputum and oesophagal reflux in children, which increases the probability of pathogens entering the lung tissues and terminal bronchi, thereby further increasing the risk of VAP [20]. Children with invasive operations are prone to VAP, which may be related to the aspiration and regurgitation of colonizing bacteria, the contamination of mechanical ventilation pipes, and the improper operations of medical staff [21, 22]. Glucocorticoids have effects of anti-inflammatory, antiviral, antishock, and immune suppression, but the inappropriate use will reduce the body defence function of children and interfere with electrolyte balance and energy metabolism in 
TABLE 3: Univariate analysis of VAP diagnosis and treatment in the pediatric ICU.

\begin{tabular}{|c|c|c|c|c|}
\hline Factors of diagnosis, treatment, and medication & VAP group $(n=49)$ & Non-VAP group $(n=106)$ & $X^{2}$ & $P$ \\
\hline Methods of nutritional support (cases) & & & 2.7389 & 0.0979 \\
\hline Parenteral nutrition & 35 & 61 & & \\
\hline Enteral nutrition & 14 & 45 & & \\
\hline Intubation method (cases) & & & 1.2000 & 0.2733 \\
\hline Mouth & 25 & 64 & & \\
\hline Transnasal & 24 & 42 & & \\
\hline Duration of mechanical ventilation (cases) & & & 10.9749 & 0.0009 \\
\hline$<7 \mathrm{~d}$ & 17 & 67 & & \\
\hline$\geq 7 \mathrm{~d}$ & 32 & 39 & & \\
\hline Duration of stay in the ICU (cases) & & & 6.9206 & 0.0085 \\
\hline$<48 \mathrm{~h}$ & 18 & 63 & & \\
\hline$\geq 48 \mathrm{~h}$ & 31 & 43 & & \\
\hline \multicolumn{5}{|l|}{ Invasive operations (cases) } \\
\hline Yes & 38 & 53 & 10.4927 & 0.0012 \\
\hline No & 11 & 53 & & \\
\hline Application of antibiotics (cases) & & & 0.8126 & 0.3674 \\
\hline Exclusive use & 26 & 48 & & \\
\hline Jointly use & 23 & 58 & & \\
\hline Application of hormone (cases) & & & 22.0874 & 0.001 \\
\hline Yes & 36 & 35 & & \\
\hline No & 13 & 71 & & \\
\hline Application of antibiotics (cases) & & & 20.8232 & 0.001 \\
\hline Yes & 22 & 86 & & \\
\hline No & 27 & 20 & & \\
\hline Atomizing inhalation (cases) & & & 2.8590 & 0.0909 \\
\hline Yes & 19 & 63 & & \\
\hline No & 30 & 43 & & \\
\hline
\end{tabular}

TABLE 4: Variable assignment of VAP.

\begin{tabular}{lc}
\hline Variables & Explanation of assignment \\
\hline Age & $<7 \mathrm{yd}=1, \geq 7=0$ \\
Underlying diseases & $\mathrm{YES}=1, \mathrm{NO}=0$ \\
Experience of blood transfusion & $\mathrm{YES}=1, \mathrm{NO}=0$ \\
Malnutrition & $\mathrm{YES}=1, \mathrm{NO}=0$ \\
Duration of mechanical ventilation & $\geq 7 \mathrm{~d}=1,<7 \mathrm{~d}=0$ \\
Time of admission to the ICU & $\geq 48 \mathrm{~h}=1,<48 \mathrm{~h}=0$ \\
Invasive operations & $\mathrm{YES}=1, \mathrm{NO}=0$ \\
Use of hormones & $\mathrm{YES}=1, \mathrm{NO}=0$ \\
Application of antibiotics & $\mathrm{YES}=1, \mathrm{NO}=0$ \\
\hline
\end{tabular}

the body. This will increase bacterial infection in children and lead to bacterial resistance, resulting in adverse outcomes such as severe pneumonia and immunodeficiency $[23,24]$ and rising VAP incidence in the pediatric ICU. The use of antacids increases VAP incidence, and its dominant reason may be that antacids can increase the $\mathrm{PH}$ value of gastric juice, thus weakening the gastric acid barrier in children. This can lead to gastrointestinal dysbacteriosis in children, leading to infections with multidrug-resistant bacteria such as Acinetobacter baumannii and Klebsiella pneumonia. On the other hand, the increased application of antacids may also lead to the displacement of the intestinal flora of children or the migration of colonizing bacteria to the lungs caused by oesophagal reflux, thus increasing VAP's probability $[25,26]$.

Given the independent risk factors for the occurrence of VAP in the pediatric ICU, our hospital has organized and formed the following targeted nursing countermeasures based on routine care. (1) Strengthening the humidification management of artificial airways and adjusting the total amount of humidification in line with the children's disease stouts and the viscosity of sputum. Appropriate airbag inflating pressure should be used, an adequate airtight artificial airway should be formed, the probability of external bacteria entering the respiratory tract should be reduced, and the respiratory infections caused by hand contamination should be prevented; subglottic sputum aspiration should be used, which can effectively clear the sputum and reduce the probability of pulmonary disease; intermittent shutdowns should be taken, the changes in the children's vital signs should be closely monitored, the intubation and ventilator should be removed as soon as possible to reduce the treatment time of mechanical ventilation, and the recovery of children's spontaneous breathing should be promoted $[27,28]$. (2) The aseptic operations should be strictly followed when performing invasive operations. The pipeline should be checked immediately after operation to confirm whether it is polluted, the nursing should be strengthened, and the channel should be disinfected in time to prevent the reproduction of colonizing bacteria, thereby reducing the risk of VAP in children. (3) The sensitive drugs should be selected following the detection results of pathogenic bacteria in children, the changes and drug resistance of infected strains should be monitored by the dynamic method, and timely adjustments should be made to the types, duration, and dosage of hormones. (4) Gastric mucosal protectants instead of antacids should be used according to the child's condition to prevent 
TABle 5: Multivariate logistic regression analysis of VAP in the pediatric ICU.

\begin{tabular}{lcccccc}
\hline Factor & $\beta$ & S. E & Wald $X^{2}$ & $P$ & OR & $95 \%$ CI \\
\hline Mechanical ventilation & 1.232 & 0.421 & 8.564 & 0.003 & 3.428 & $1.502-7.824$ \\
Invasive operations & 1.496 & 0.425 & 12.390 & $\leq 0.001$ & 4.464 & $1.941-10.286$ \\
Application of hormones & 2.137 & 0.736 & 8.431 & 0.004 & 8.474 & $2.003-35.858$ \\
Application of antacids & 1.535 & 0.524 & 8.581 & 0.003 & 4.641 & $1.662-12.962$ \\
\hline
\end{tabular}

TABLE 6: Comparison of the treatment of children in the ICU between the two groups.

\begin{tabular}{lcc}
\hline Group & Length of hospital stay $(\mathrm{d})$ & Hospital expenses (ten thousand Yuan) \\
\hline VAP group $(n=49)$ & $20.92 \pm 4.16$ & $4.58 \pm 1.04$ \\
Non-VAP group $(n=106)$ & $15.24 \pm 3.77$ & $3.32 \pm 0.43$ \\
T & 8.4383 & 10.6822 \\
$P$ & 0.001 & 0.001 \\
\hline
\end{tabular}

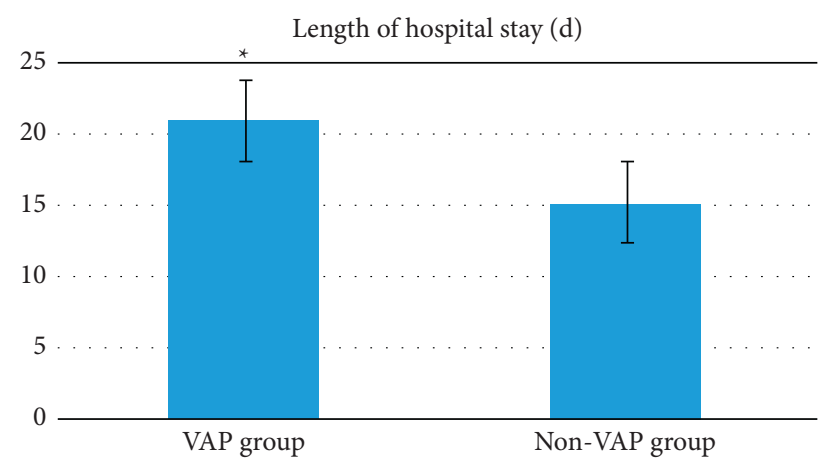

(a)

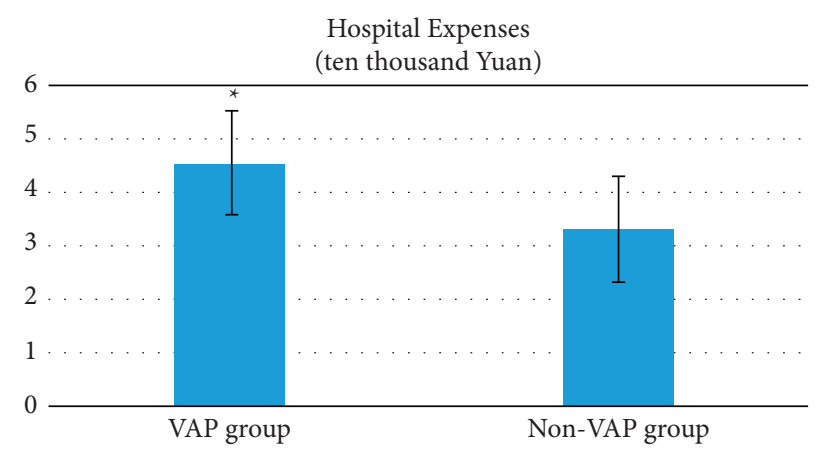

(b)

Figure 1: Comparison of the treatment of children in the ICU between the two groups. Compared with the non-VAP group, ${ }^{*} P<0.05$.

gastrointestinal bleeding; dietary guidance and oral care should be strengthened. According to studies, the nursing countermeasures can remarkably reduce the incidence of VAP and prevent secondary infection, which is an effective measure to improve the patient's quality of life $[29,30]$.

\section{Conclusions}

To conclude, children admitted to the pediatric ICU have a high VAP incidence; the primary pathogenic bacteria are Gram-negative bacteria. As the occurrence of VAP is closely related to a variety of factors, we should take targeted nursing countermeasures to reduce the duration of mechanical ventilation and the frequency of invasive operations and use the hormone and antacids rationally to reduce the risk of VAP and improve the prognosis.

\section{Data Availability}

The data used to support this study are available from the corresponding author upon request.

\section{Conflicts of Interest}

The authors declare no conflicts of interest.

\section{Authors' Contributions}

Rong Chen and Yu Liu contributed equally to this study.

\section{References}

[1] R. X. Alecrim, M. Taminato, A. Belasco, M. C. B. Longo, D. M. Kusahara, and D. Fram, "Strategies for preventing ventilator-associated pneumonia: an integrative review," Revista Brasileira de Enfermagem, vol. 72, no. 2, pp. 521-530, 2019.

[2] C. F. de Lacerda Vidal, A. K. d. L. Vidal, J. G. d. M. Monteiro Jr et al., "Impact of oral hygiene involving toothbrushing versus chlorhexidine in the prevention of ventilator-associated pneumonia: a randomized study," BMC Infectious Diseases, vol. 17, no. 1, p. 112, 2017.

[3] M. Chomton, D. Brossier, M. Sauthier et al., "Ventilatorassociated pneumonia and Events in pediatric intensive care," Pediatric Critical Care Medicine, vol. 19, no. 12, pp. 11061113, 2018.

[4] G. Vijay, A. Mandal, J. Sankar, A. Kapil, R. Lodha, and S. K. Kabra, "Ventilator associated pneumonia in pediatric intensive care Unit: incidence, risk factors and Etiological Agents," Indian Journal of Pediatrics, vol. 85, no. 10, pp. 861-866, 2018.

[5] G. L. Bassi, E. A. Xiol, F. Pagliara, Y. Hua, and A. Torres, "Body position and ventilator-associated pneumonia 
prevention," Seminars in Respiratory and Critical Care Medicine, vol. 38, pp. 371-380, 2017.

[6] R. Soussan, C. Schimpf, B. Pilmis et al., "Ventilator-associated pneumonia: the central role of transcolonization," Journal of Critical Care, vol. 50, pp. 155-161, 2019.

[7] B. François, A. Cariou, R. Clere-Jehl et al., "Le Gouge A and CRICS-TRIGGERSEP Network and the ANTHARTIC study group prevention of Early ventilator-associated pneumonia after Cardiac Arrest," New England Journal of Medicine, vol. 381, pp. 1831-1842, 2019.

[8] Y. Fan, F. Gao, Y. Wu, J. Zhang, M. Zhu, and L. Xiong, "Does ventilator-associated event surveillance detect ventilator-associated pneumonia in intensive care units? A systematic review and meta-analysis," Critical Care, vol. 20, no. 1, p. 338, 2016.

[9] F. Álvarez-Lerma, M. Palomar-Martínez, M. Sánchez-García et al., "Prevention of ventilator-associated pneumonia: the Multimodal approach of the Spanish ICU "pneumonia Zero" Program,” Critical Care Medicine, vol. 46, pp. 181-188, 2018.

[10] R. H. Kallet, "Ventilator Bundles in Transition: from prevention of ventilator-associated pneumonia to prevention of ventilator-associated Events," Respiratory Care, vol. 64, no. 8, pp. 994-1006, 2019.

[11] M.-Y. Wang, L. Pan, and X.-J. Hu, "Chest physiotherapy for the prevention of ventilator-associated pneumonia: a metaanalysis," American Journal of Infection Control, vol. 47, no. 7, pp. 755-760, 2019.

[12] C.-E. Luyt, G. Hékimian, D. Koulenti, and J. Chastre, "Microbial cause of ICU-acquired pneumonia," Current Opinion in Critical Care, vol. 24, no. 5, pp. 332-338, 2018.

[13] S. Burja, T. Belec, N. Bizjak, J. Mori, A. Markota, and A. Sinkovič, "Efficacy of a bundle approach in preventing the incidence of ventilator associated pneumonia (VAP)," Bosnian Journal of Basic Medical Sciences, vol. 18, pp. 105-109, 2018.

[14] E. Kocaçal Güler and G. Türk, "Oral chlorhexidine against ventilator-associated pneumonia and Microbial Colonization in intensive care patients," Western Journal of Nursing Research, vol. 41, pp. 901-919, 2019.

[15] A. Okgün Alcan, F. Demir Korkmaz, and M. Uyar, "Prevention of ventilator-associated pneumonia: use of the care bundle approach," American Journal of Infection Control, vol. 44, pp. e173-e176, 2016.

[16] A. Haghighi, V. Shafipour, M. Bagheri-Nesami, A. Gholipour Baradari, and J. Yazdani Charati, "The impact of oral care on oral health status and prevention of ventilator-associated pneumonia in critically ill patients," Australian Critical Care, vol. 30, no. 2, pp. 69-73, 2017.

[17] L. Ayzac, R. Girard, L. Baboi et al., "Ventilator-associated pneumonia in ARDS patients: the impact of prone positioning. A secondary analysis of the PROSEVA trial," Intensive Care Medicine, vol. 42, no. 5, pp. 871-878, 2016.

[18] N. Malhan, M. Usman, N. Trehan et al., "Oral care and ventilator-associated pneumonia," American Journal of Therapeutics, vol. 26, pp. 604-607, 2019.

[19] V. Kumar, "Ventilator associated pneumonia in children: Current status and Future Prospects," Indian Journal of Pediatrics, vol. 85, no. 10, pp. 830-831, 2018.

[20] A. Čiginskienè, A. Dambrauskienè, J. Rello, and D. Adukauskiene, "Ventilator-associated pneumonia due to drug-resistant Acinetobacter baumannii: risk factors and mortality relation with resistance Profiles, and independent predictors of in-hospital mortality," Medicina (Kaunas, Lithuania), vol. 55, p. 49, 2019.
[21] R. Chacko, A. Rajan, P. Lionel, M. Thilagavathi, B. Yadav, and J. Premkumar, "Oral decontamination techniques and ventilator-associated pneumonia," British Journal of Nursing, vol. 26, no. 11, pp. 594-599, 2017.

[22] T. H. Craven, G. Wojcik, J. McCoubrey et al., "Ventilatorassociated pneumonia surveillance using two methods," Journal of Hospital Infection, vol. 104, no. 4, pp. 522-528, 2020.

[23] D. P. Pozuelo-Carrascosa, Á. Herráiz-Adillo, C. AlvarezBueno, J. M. Añón, V. Martínez-Vizcaíno, and I. CaveroRedondo, "Subglottic secretion drainage for preventing ventilator-associated pneumonia: an overview of systematic reviews and an updated meta-analysis," European Respiratory Review, vol. 29, no. 155, p. 190107, 2020.

[24] E. Iosifidis, G. Pitsava, and E. Roilides, "Ventilator-associated pneumonia in neonates and children: a systematic analysis of diagnostic methods and prevention," Future Microbiology, vol. 13, no. 12, pp. 1431-1446, 2018.

[25] Y. Xu, C. Lai, G. Xu et al., "Risk factors of ventilator-associated pneumonia in elderly patients receiving mechanical ventilation," Clinical Interventions in Aging, vol. Volume 14, pp. 1027-1038, 2019.

[26] M. Klompas, "Oropharyngeal decontamination with Antiseptics to prevent ventilator-associated pneumonia: Rethinking the Benefits of chlorhexidine," Seminars in Respiratory and Critical Care Medicine, vol. 38, no. 03, pp. 381-390, 2017.

[27] C. Cillóniz, C. Dominedò, and A. Torres, "An overview of guidelines for the management of hospital-acquired and ventilator-associated pneumonia caused by multidrug-resistant Gram-negative bacteria," Current Opinion in Infectious Diseases, vol. 32, pp. 656-662, 2019.

[28] A. Rouzé, I. Martin-Loeches, and S. Nseir, "Airway Devices in ventilator-associated pneumonia Pathogenesis and prevention," Clinics in Chest Medicine, vol. 39, pp. 775-783, 2018.

[29] S. Osman, Y. M. Al Talhi, M. AlDabbagh, M. Baksh, M. Osman, and M. Azzam, "The incidence of ventilator-associated pneumonia (VAP) in a tertiary-care center: comparison between pre- and post-VAP prevention bundle," Journal of Infection and Public Health, vol. 13, no. 4, pp. 552-557, 2020.

[30] A. Coppadoro, G. Bellani, and G. Foti, "Non-pharmacological Interventions to prevent ventilator-associated pneumonia: a literature review," Respiratory Care, vol. 64, no. 12, pp. 1586-1595, 2019. 